\title{
JUURNAL.RU
}

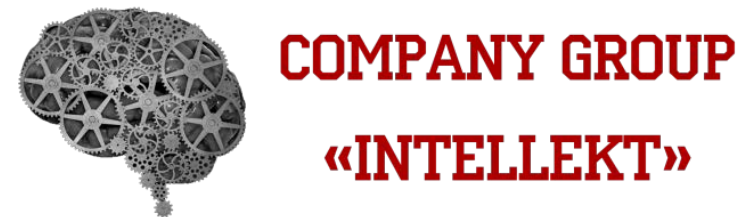
Магомадова 3.С., Джабагова С.С. ПИ ФГБОУ ВО ЧГПУ
Россия

doi: 10.18411/lj2016-3-88

\section{Структурные компоненты АСУ современного инновационного вуза}

В условиях рыночной экономики, проблемы управления ВУЗом приобретают первостепенное значение. В статье рассмотрена одна из сложнейших на сегодняшний момент систем управления вузом автоматизированная информационная система «Аксиома», разработанная и функционирующая на базе Национального исследовательского технологического университета «Московский институт стали и сплавов».

Ключевые слова: вуз, автоматизированная система управления, автоматизированные, автоматизированная информационная система.

Автоматизация основных направлений деятельности является одним из приоритетных направлений развития современного инновационного вуза. Автоматизированные системы управления вузом (АСУ) прошли в нашей стране долгий путь эволюции, начиная ещё с Советских времён. Однако, основные этапы современной истории АСУ начинаются с 90- ых годов XX в., когда основной платформой для разработок стала IBM РС. С тех пор в вузах страны сменились АСУ, в среднем, трёх поколений. Однако, на современном этапе функциональные и структурные особенности реализации вузовских автоматизированных систем предопределяют многообразие и сложная взаимосвязь реализуемых в высшем учебном заведении бизнес- процессов.

На наш взгляд, наиболее сложной и отвечающей современным требованиям к образовательному процессу в вузе на сегодняшний момент 
является АИС «Аксиома», разработанная сотрудниками МИСИС совместно с компанией «МНПП НАМИП» - Новые системы Автоматизации, Моделирования и Проектирования и функционирующая на базе Национального исследовательского технологического университета «Московский институт стали и сплавов» [3]. АИC «Аксиома», разработана на базе SOA-платформы iJaNet и предназначена для комплексного решения вопросов управления учебной и научной деятельностью и контингентом учащихся, а также для организации оперативного обмена данными в едином информационном пространстве вуза. Следует так же отметить, что для решения вопросов рационального использования IT-бюджетов и использования возможностей облачных вычислений при разработке АИC «Аксиома» была апробирована SaaS - модель построения информационной инфраструктуры [1]. В целом, АИС «Аксиома» имеет в своём составе следующие подсистемы:

- «Управление контингентом учащихся»;

- «Учет текущей успеваемости и посещаемости»;

- «Расчет стипендии»;

- «Планирование учебного процесса»;

- «Разработка и внедрение системы автоматизации деятельности управления науки».

Управление учебным процессом в условиях перехода на многоуровневую систему высшего образования характеризуется необходимостью обеспечения сквозного учета контингента студентов (в том числе магистров и студентов, получающих второе и более высшее образование), накопления истории изменений и истории взаимоотношений вуза со студентами, организации оперативного аналитического учета и контроля текущей успеваемости студентов и посещаемости занятий. На основе анализа опыта разработки и функционирования данной системы [2], можно отметить, что в АИС «Аксиома» включены готовые к использованию сервисы, разделенные на следующие функциональные группы (табл.1): 
Таблииа 1

Основные сервисы АИС «Аксиома»

\begin{tabular}{|c|c|}
\hline Сервис & Основные выполняемые функции \\
\hline $\begin{array}{l}\text { Приемная } \\
\text { комиссия }\end{array}$ & $\begin{array}{l}\text { - работа с личными делами абитуриентов (анкетные данные, сведения об образовании, } \\
\text { контактная информация и др.); } \\
\text { - подготовка к проведению и обработка результатов вступительных испытаний; } \\
\text { - учет результатов вступительных испытаний, влияющих на результаты конкурсного } \\
\text { отбора; } \\
\text { - формирование конкурсного ряда абитуриентов в соответствии с правилами приема; } \\
\text { - подготовка документов к зачислению абитуриентов; } \\
\text { - печать документов (заявление, анкета абитуриента, расписка о принятии документов, } \\
\text { журнал регистрации абитуриентов и пр.); } \\
\text { - статистическая обработка информации по результатам приема и др. }\end{array}$ \\
\hline $\begin{array}{l}\text { Управление } \\
\text { контингентом }\end{array}$ & $\begin{array}{ll}- & \text { формирование и ведение единой карточки студента; } \\
- & \text { сквозной учет контингента студентов; } \\
- & \text { формирование различных отчетов по движению контингента студентов; } \\
- & \text { формирование отчетности по трудоустройству выпускников. }\end{array}$ \\
\hline $\begin{array}{l}\text { Текущая } \\
\text { успеваемость }\end{array}$ & $\begin{array}{l}- \text { ведение реестра (журнала) текущей успеваемости студентов путем ввода } \\
\text { информации вручную либо путем сканирования и распознавания информации с } \\
\text { соответствующих журналов (по результатам выполнения домашних заданий, } \\
\text { практикумов, коллоквиумов и других контрольных мероприятий); } \\
-\quad \text { формирование различных отчетов по текущей успеваемости студентов и т. д. }\end{array}$ \\
\hline $\begin{array}{l}\text { Текущая } \\
\text { посещаемость }\end{array}$ & $\begin{array}{l}- \text { ввод результатов текущей посещаемости студентов путем ввода информации } \\
\text { вручную либо путем сканирования и распознавания информации с журналов } \\
\text { посещаемости; } \\
\text { - } \quad \text { формирование различных отчетов по текущей посещаемости студентов и т. д. }\end{array}$ \\
\hline $\begin{array}{l}\text { Сессионная } \\
\text { успеваемость }\end{array}$ & $\begin{array}{l}\text { - ввод результатов сессионной успеваемости путем ввода информации вручную } \\
\text { либо путем сканирования и распознавания информации с зачетных и экзаменационных } \\
\text { ведомостей; } \\
-\quad \text { формирование различных отчетов по контингенту студентов на основе данных } \\
\text { сессионной успеваемости. }\end{array}$ \\
\hline $\begin{array}{l}\text { Выпуск } \\
\text { документов }\end{array}$ & $\begin{array}{l}\text { - формирование документов государственного образца о высшем профессиональном } \\
\text { образовании, в том числе для иностранных студентов; } \\
\text { - организация выпуска на бумажных носителях документов об образовании } \\
\text { (диплом, приложение к диплому, академическая справка, выписка и пр.); } \\
\text { - подготовка различных отчетов о выпуске документов, в том числе «Книга } \\
\text { регистрации дипломов» }\end{array}$ \\
\hline Учебный процесс & 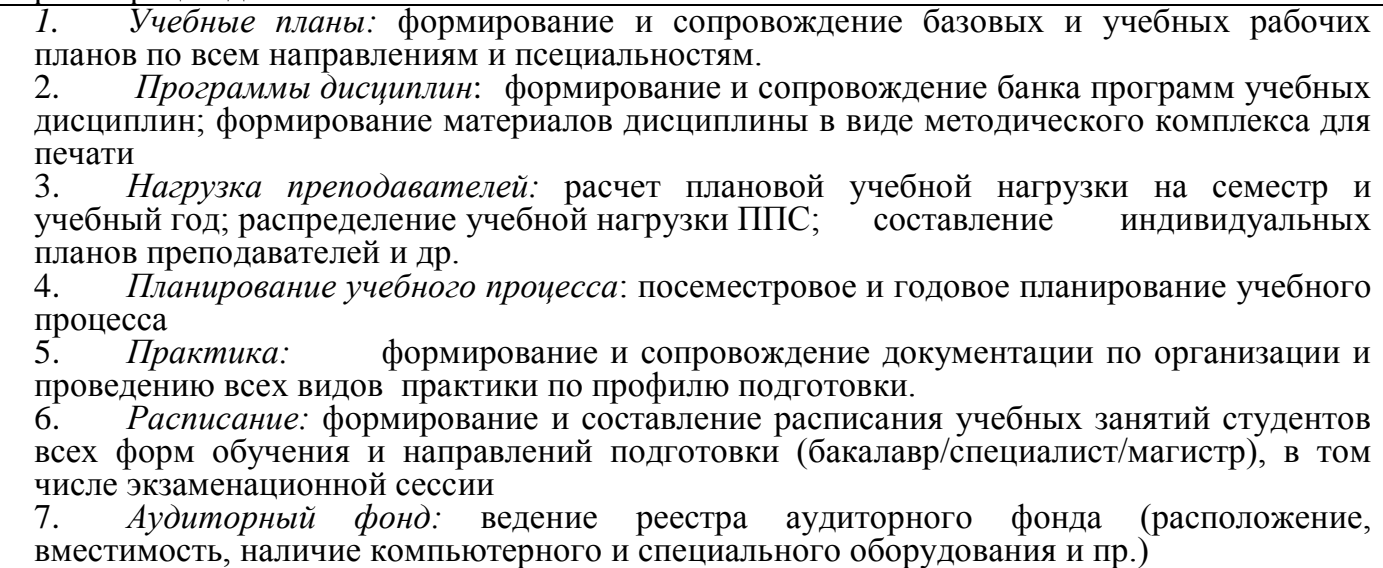 \\
\hline $\begin{array}{l}\text { Довузовское } \\
\text { обучение }\end{array}$ & $\begin{array}{l}\text { - } \quad \text { работа с личными делами слушателей (анкетные данные, сведения об образовании, } \\
\text { контактная информация и др.); } \\
-\quad \text { подготовка документов слушателей к зачислению; } \\
-\quad \text { учет выполнения учебной работы и контроль за своевременным выполнением } \\
\text { учебного плана; } \\
-\quad \text { учет результатов промежуточных и итоговых испытаний слушателей }\end{array}$ \\
\hline Аспирантура & $\begin{array}{l}\text { - } \quad \text { работа с личными делами аспирантов, докторантов и соискателей (анкетные } \\
\text { данные, сведения об образовании и др.); } \\
\text { - подготовка сводных отчетов о работе аспирантуры, отображающих статистику } \\
\text { работы по подготовке научных кадров }\end{array}$ \\
\hline $\begin{array}{l}\text { Дополнительное } \\
\text { образование }\end{array}$ & 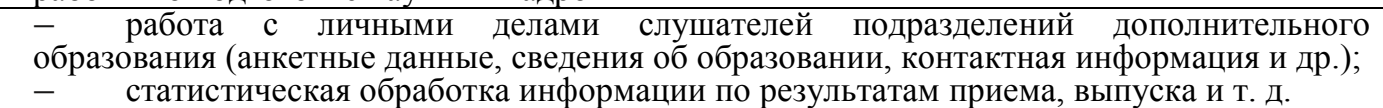 \\
\hline
\end{tabular}


Хотелось бы так же отметить, что в данной статье рассмотрены возможности АИС «Аксиома», в основном, касающиеся образовательного процесса. Вместе с тем, данная система предназначена для управления так же и научной деятельностью вуза: ведения и сопровождения управленческого и финансового учета результатов госбюджетных и хоздоговорных научноисследовательских работ; формирования и учета документации по реализации международных учебных и научно-исследовательских проектов; учета обучения/стажировки/практики учащихся иностранных государств; учета обучения/стажировки/практики учащихся в иностранных вузах в рамках программ международного обмена и др. сведения.

Так же во всех вузах используются отдельные автоматизированные системы, связанные с работой вспомогательных служб:

- «1С Бухгалтерия» - программное решение для комплексной автоматизации ведения бухгалтерского учёта и учёта различных видов финансовохозяйственной деятельности вуза; расчёта заработной платы сотрудников, стипендии студентов, налоговой базы;

- Автоматизированная информационная библиотечная система;

- Система учёта публикационной активности профессорскопреподавательского состава;

- Автоматизированные системы, контролирующие контингент студентов, проживающих в общежитии и др.

Резюмируя вышеизложенное отметим, что АСУ современного вуза - это сложные системы, которые разрабатываются или на базе самих вузов, или на специализированных фирмах, но практически всегда - это комплекс отдельных автоматизированных систем, интегрированных в единую систему и подстроенную под специфику вуза. 


\section{Литература:}

1. Иванченко Д. А. Построение информационной инфраструктуры вуза с применением модели SaaS // Высшее образование в России. 2010. № 10. С. 11-12.

2. Иванченко Д.А. Оптимизация построения информационной системы управления вузом: концептуальные подходы //Университетское управление: практика и анализ. 2011. № 2. С. 40-48.

3. МНПП НАМИП установила обновленную версию модуля «Приемная комиссия» в НИТУ «МИСиС» - http://www.tadviser.ru/index.php 